\title{
Testing Convergence in Post-War Transition Country
}

\author{
Muamer Halilbasic*, Emir Agic \\ Sarajevo School of Economics and Business, University of Sarajevo, Sarajevo, Bosnia and Herzegovina \\ Email address: \\ muamer.halilbasic@efsa.unsa.ba (M. Halilbasic),emir.agic@efsa.unsa.ba (E. Agic) \\ ${ }^{*}$ Corresponding author
}

\section{To cite this article:}

Muamer Halilbasic, Emir Agic. Testing Convergence in Post-War Transition Country. International Journal of Business and Economics Research. Vol. 10, No. 5, 2021, pp. 203-208. doi: 10.11648/j.ijber.20211005.15

Received: September 19, 2021; Accepted: October 13, 2021; Published: October 28, 2021

\begin{abstract}
The issue of economic convergence has been widely analyzed by the researchers. Convergence hypothesis has been tested at different levels - global, national, regional and local. This paper is analyzing local economic convergence in Bosnia and Herzegovina $(\mathrm{BiH})$ in last three decades. In this period the country was facing twofold transition: from war to peace and from socialism to market economy. The regression and distributional approach to convergence analysis are combined. The first hypothesis research is testing is that poor municipalities grow faster comparing to rich municipalities - unconditional beta convergence. Second hypothesis is that dispersion of local per capita GDP decreases over time - sigma convergence. To further investigate the issue and check the changes in the distribution, several visual inspection instruments were also used. The research findings are inconclusive. While regression analysis provides some evidence for unconditional beta-convergence, in a case of sigma convergence, results are mixed. This is related to significant structural changes country went through, firmly confirmed with the transitional probability matrix data. Findings confirm the necessity for combining different approaches and instruments while analysing convergence. From the specific country perspective, research results can be used as a strong argument for the necessity of new more balanced regional development policy.
\end{abstract}

Keywords: Beta and Sigma Convergence, Local Government, Bosnia and Herzegovina

\section{Introduction}

Economic convergence can be defined as a propensity of less developed localities (countries, regions) to grow faster comparing to more developed localities. This paper analyzes local economic convergence in Bosnia and Herzegovina in post 1992-1995 war period. Dayton Peace Agreement that ended the war introduced completely new administrative setting of the country. Two entities were created and one district with the special status, in addition. Border between the entities was drown based on the ethnicities predominantly living in a certain areas and military standing at the end of the war. Entities border crossed natural economic regions and, in many cases, even the pre-war municipal borders. As a result, regional economic connections were abrupt and more than thirty new municipalities were created. Some of the newly created municipalities have just a few thousands or few hundreds inhabitants. While, one of the entities is highly centralized, the other is further divided on ten cantons with significant legislative power, own constitutions, assemblies, etc. Two autonomous local government systems were created with limited connections between them. Twenty five years after the war ended single economic area in the country is still not completely renewed.

In the late 1990s and early 2000s the country was simultaneously facing twofold transition. In addition of war to peace, transition from socialism to market economy was also in place. The war-torn, disintegrated economy, which has lost pace with world trends, has been a very difficult terrain for transitional changes. The country opted for mass voucher privatization of state-owned enterprises. The privatization was implemented on the entity level with almost no coordination. Twelve huge industrial conglomerates that dominated country's economic structure were first dismantled and then privatized in parts. Generally, the results of the transition are disappointing. The country is lagging behind the neighbors in the process of accessing the EU. Balanced regional development, although a constitutional obligation, is very low on the list of both entities governments' priorities. All of these had significant impact on development trajectories on local, regional and national level. 
This paper investigates how these specific circumstances the country was facing in last few decades affected the distribution of income and convergence processes on local level. The paper is organized as follows. After a short introductory notes, second section presents the theoretical background on economic convergence and previous research findings. Applied methodology and the data used are explained in the third section. Empirical findings are outlined and discussed in fourth section. The last section conclude.

\section{Literature Review}

The issue of economic convergence has been intensively analyzed by the researchers in the last few decades. Researches were trying to find factors explaining the growth rates of developed countries, but also the differences between developed and developing countries growth rates. Construction of neoclassical growth model in 1960s provided theoretical background for empirical analysis of convergence $[31,32,8]$. Key assumption of the model are diminishing returns on the capital as production factor. Growth process in the long run, based on this assumption, should lead to a steady-state. Growth rate in the steady state is determined by the technological progress (exogenous factor) and labor force increase. This model predicts higher growth rates for less developed economies. With the assumption of the same steady state, initial level of capital is the only difference across economies meaning that the less developed countries will grow faster, and eventually catch up with more developed ones. This is because less developed countries are further away from their steady state - absolute convergence. More realistic assumption is that different economies, because of the differences in technology, saving rates, etc., have different steady states. With this assumption, the neoclassical growth model predicts that less developed economies will have higher growth rates, only if these differences are controlled for conditional convergence [30].

\subsection{Beta Convergence}

Convergence has been analyzed using two different approaches - regression and distributional approach. First approach is using different methods for the neoclassical growth model convergence prediction testing [5, 3, 4]. These researches are assessing whether different localities are converging towards steady state paths (so called $\beta$-convergence) and what is the speed of convergence.

Research evidence seems to suggest that there is no absolute convergence. There are some evidence on conditional convergence. However, the convergence speed is rather low. For example, after controlling for primary and secondary school enrolment ratio, saving rate and some political variables, Sala-i-Martin [30] estimates the rate of conditional convergence at two percent per annum. Worldwide a dozen of studies have reported $\beta$-convergence when analyzing groups of regional economies [30, 13, 12].

Evidence of $\beta$-convergence is reported in most researches focusing within specific EU countries [9, 18, 15, 25]. However, the estimated values of the convergence rate are very different. When moving to EU level, evidence of conditional convergence are often found [1, 24, 16, 11, 20, 21]. Again, research results suggests profound changes in convergence pattern over time. Also, it seems that, comparing to other regions, convergence speed in Europe is much lower.

Matkowski and Prochniak [19] show that between 1993 and 2001 accession countries grew faster than older EU members confirming strong economic convergence. Recent research [6] reveal two different clusters among EU countries: the old and new members. Research conducted by Nagy and Siljak [23] provide some evidence for the absolute convergence of the Western Balkan countries towards the EU-15. Bićanić et al. [7] investigate the convergence between former Yugoslavia republics. They found no convergence evidence. Interestingly, convergence developed with the independence.

Based on the vast panel of existing studies [14], it can be concluded that results obtained using the regression approach strongly depend on the model specification (type of convergence tested - absolute or conditional, variables included in the model, spatial effects inclusion), time period covered and localities considered, used dataset, etc.

An important critique of regression approach is concentrated on its informative content. Several studies indicate that a negative relationship between countries growth rates and initial level of development does not necessary mean a reduction in the cross-sectional variance [17, 27]. This approach simply describe how certain economy converges to its own steady state. It provides no information whatsoever on the distribution dynamics. To avoid this shortcoming, some researchers are combining this approach with the distribution approach explained bellow.

\subsection{Sigma Convergence}

Second approach for analyzing economic convergence is the distributional approach (often labeled as Sigma-convergence. This approach examines directly over time changes in cross-sectional distribution of income per capita. Focus is on the change in the distribution external shape and its internal dynamics [28, 29, 26].

Beta and Sigma-convergence are closely related. Beta-convergence is necessary but not sufficient for Sigma-convergence. This is because, as we already mentioned, economies can converge towards different steady-states (conditional beta convergence). Second reason is that economies can, generally, mutually converge but sudden shocks diverge them apart.

Standard deviation and coefficient of variation of state or regional income are the most frequently used summary measures of Sigma-convergence. Several other measures, such as Atkinson index, Theil index and Mean Logarithmic Deviation, reveal interesting distribution properties and are used by the researchers $[10,33]$. These summary measures provide a synthesis of the information and are relatively easy to calculate. However, they may not rank two distributions the same way since the weighting schemes and implicit welfare functions vary across the measures. Also, they are not suitable 
for describing movements of observational units within the distribution. To provide more details about the mechanisms at work in the convergence process visual inspection instruments, such as non-parametric estimation of density functions, cumulative density functions and Salter graphs, can be used. After assessing pros and coins of different instruments, Monfort [22] concludes that single measure is not enough for the true convergence assessment. Rather it has to be based on a use (and sound interpretation) of set of complementary instruments.

\section{Methodology and Data}

Our analysis is focused on Bosnia and Herzegovina. A country with just over 3 million inhabitants and a few economic regions (based on to research conducted in 1980s). Having in mind questionable statistical significance if inequality measures are computed on too few observations, economic convergence in this paper is analyzed on local government level. This approach also has its own drawbacks. The most important is that in some cases substantial portion of local GDP can be attributable to commuters. Hence, the concept of GDP (proxy for the income) per head becomes more difficult to interpret on this level of aggregation.

Lack of the local level data and the need for in-depth distribution analysis determined applied methodology. The research is actually combining regression and distributional approach to convergence analysis. Under the regression approach the hypothesis we are testing is as follows:

$\mathrm{H1}$ : Poor $\mathrm{BiH}$ municpalities grow faster comparing to rich municipalities.

Beta-convergence measurement is based on the estimation of a following growth equation:

$$
\frac{1}{T} \ln \left(\frac{Y_{i T}}{Y_{i 0}}\right)=\alpha+\beta \ln Y_{i 0}+\mathcal{E}_{i}
$$

where

$y_{i, o}$ and $y_{i, t}$ are the level of GDP per head in locality $i$ at the beginning and the end of the period $t$;

${ }_{i}$ is the standard error term; and

$\alpha, \beta$ are the parameters to be estimated.

Statistically significant negative relationship between the growth rate and the initial level of GDP per head $(\beta)$ is considered as the proof of a convergence process in place. The estimated value of $\beta$ is also an indicator of convergence speed - the annual rate at which localities approach their steady-state.

To avoid previously mentioned shortcomings of regression approach and the data availability on the local level, this research is following the logic of the above mentioned arguments for combining regression and distributional analysis. The following hypotheses has been tested under the distributional approach:

$\mathrm{H} 2$ : Dispersion of GDP pc across $\mathrm{BiH}$ municipalities has been decreasing in last three decades.

Several summary measures were first used. The first is coefficient of variation - a normalised measure of dispersion of a probability distribution. As a measure of inequality in the distribution Gini coefficient was used. Sine these summary measures do not allow for an in-depth assessment of the movements of observational units within the distribution, two visual inspection instruments, non-parametric estimation of density functions and cumulative density functions, are also used. This technique is based on the implicit assumption that each data point is the center of normalised density function, referred to as the kernel. Densities are then added vertically to produce Gaussian (stochastic) kernel density estimation of the distribution [2].

Data base is consisted of 106 observations (municipalities) for three different years - 1990, 2010 and 2020. Since inequality/disparity measures are in general sensitive to the number of observations, to ensure results comparability, GDP pc data for 2010 and 2020 in a case of newly formed municipalities were grouped. Data on local GDP in 1990 are taken from official statistics. GDP data for 2010 and 2020 were estimated based on the number of employees and the average salary.

\section{Research Results Discussion}

Under the regression approach unconditional beta convergence $\mathrm{BiH}$ municipalities is analysed in period 1990-2020 and two sub-periods: 1990-2010 and 2010-2020. Regression results are presented in the Table 1.

Table 1. Absolute $\beta$-convergence, local per capita GDP.

\begin{tabular}{llll}
\hline & Model 1 & Model 2 & Model 3 \\
& $\mathbf{1 9 9 0 - 2 0 2 0}$ & $\mathbf{1 9 9 0 - 2 0 1 0}$ & $\mathbf{2 0 1 0 - 2 0 2 0}$ \\
\hline & $\beta(\mathrm{t})$ & $\beta(\mathrm{t})$ & $\beta(\mathrm{t})$ \\
& $-1.61 * * *$ & $-2.13 * * *$ & $-1.56 * * *$ \\
Log of initial per capita GDP & -7.112 & -5.247 & -5.829 \\
$\mathrm{R}^{2}$ & 0.327 & 0.209 & 0.239 \\
\hline
\end{tabular}

Note: $* * * \mathrm{p}<0.01, * * \mathrm{p}<0.05,{ }^{*} \mathrm{p}<0.1$

Source: Own calculations.

Regression results confirm absolute $\beta$-convergence. The $\beta$ coefficient in the period $1990-2020$ is -1.61 . This means that $\mathrm{BiH}$ municipalities converge to a common GDP per head at the rate of $1.61 \%$. Convergence rate in 1990-2010 time period is $2.13 \%$. Between 2010 and 2020 the rate is $1.56 \%$. All $\beta$ coefficients are highly significant ( $p$-value $=0.000$ ).

As mentioned before, Beta-convergence is necessary but not sufficient for Sigma-convergence. Sigma convergence was first assessed using two summary measures - coefficient of variation and Gini coefficient. The results are mixed.

Comparing the disparities between $\mathrm{BiH}$ municipalities in 1990, 2010 and 2020, it can concluded that Sigma-convergence is demonstrated. Coefficient of variation decreased from $47.26 \%$ in 1990 to $44.41 \%$ in 2010 , and further to $42.55 \%$ in 2020 .

To measure inequality of GDP (income) per head distribution across municipalities, Gini index is also calculated. The index varies between 0 and $100 \%$ were low values indicates more equal distribution. Under this measure, 
unlike with the previous one, Sigma-convergence is not confirmed. Disparities among localities first increased from $16.32 \%$ in 1990 to $25.71 \%$ in 2010 , and then slightly decreased to $24.14 \%$.

Difference in results can be explained by the main properties of the two measures. While coefficient of variation is more sensitive to changes in the mean, Gini index is more sensitive in inequality around the median/mode.

To further investigate the issue and check the changes in the distribution, two visual inspection instruments were used. Gaussian kernel estimation of the municipal GDP pc distributions in 1990, 2010 and 2020 are displayed in the Figure 1. Convergence can't be confirmed using this instrument. Frequencies around the mean are very similar in there analysed years. However, for values below $70 \%$ of $\mathrm{BiH}$ average frequencies significantly increase, indicating divergence. Close visual observation is also revealing signs of an evolution to bimodal type of distribution. This leads to a conclusion that a polarisation process is taking place. This is very interesting finding and something that requires future deeper analysis.

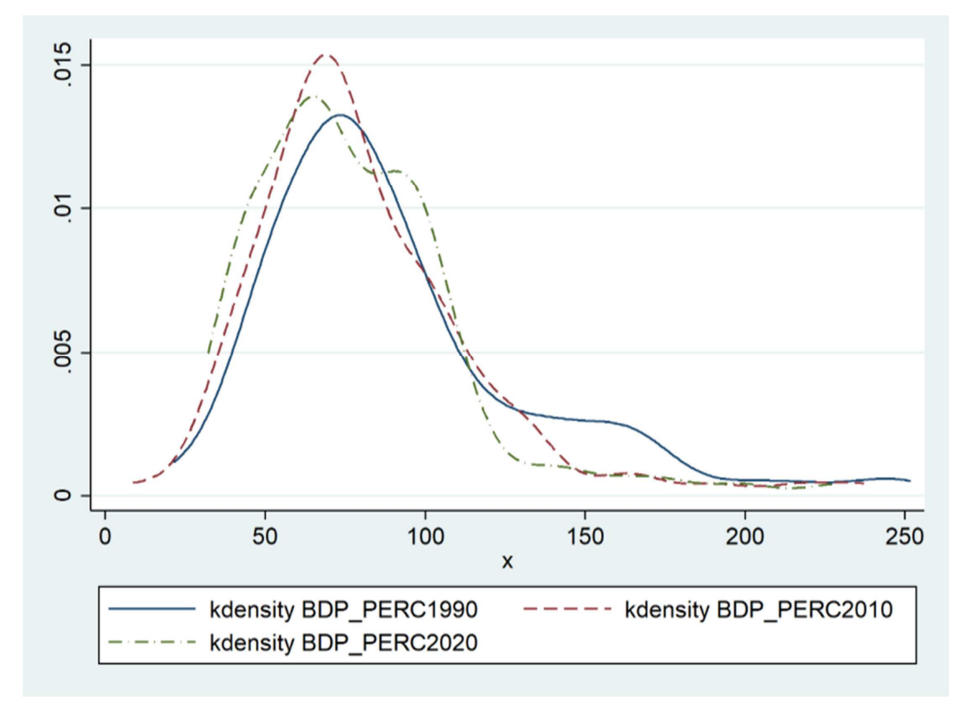

Figure 1. GDP pc: Distribution of BiH municipalities, 1990-2010-2020, Gaussian kernel estimation.

Second visual inspection instrument used is cumulative frequency analysis. The instrument shows the percentage of municipalities for which the record value of GDP per head falls below a reference value. Basically, the steeper cumulative frequency curve around the mean is the sign of smaller disparities between localities. Cumulative frequency distributions of GDP per head in a case of $\mathrm{BiH}$ municipalities in 1990, 2010 and 2020 is plotted in Figure 2.

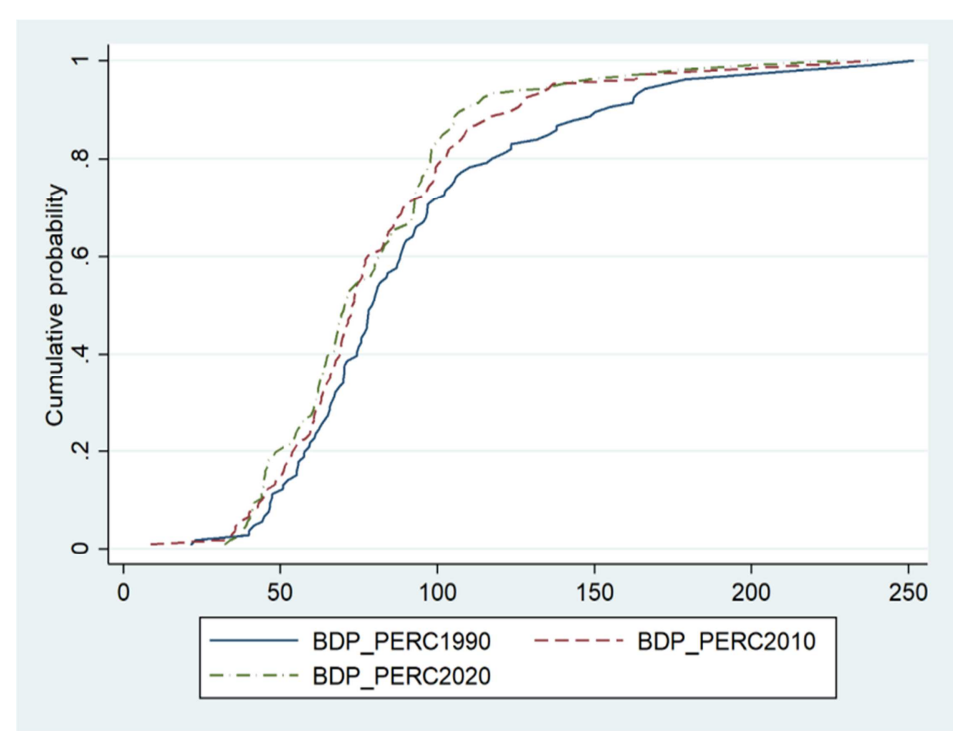

Figure 2. GDP pc: Cumulative frequency distribution of BiH municipalities, 1990-2010-2020.

The results seems to be mixed. Cumulative frequencies of GDP per head in 2010 and 2020, compared to the one from 1990, are becoming slightly steeper around $\mathrm{BiH}$ average (100).
In a way this development confirms that some convergence has occurred. On the other hand, it can also be observed that cumulative frequency corresponding to $60 \%$ of $\mathrm{BiH}$ average 
was around 0.15 . This means that $15 \%$ of the observation (i.e. municipalities) was bellow this threshold. In 2020, this figure was much higher - $25 \%$, indicating divergence at the lower bound of distribution - among poorest municipalities.
Mixed results are related to significant structural changes country went through in last several decades. This is firmly confirmed with the transitional probability matrix data presented in Tables 2 and 3.

Table 2. Transition probability matrix, BDP pc, BiH =100, 1990-2010.

\begin{tabular}{|c|c|c|c|c|c|c|}
\hline \multicolumn{7}{|l|}{ GDP pc 2010} \\
\hline GDP pc 1990 & $\%$ of regions & $0-50 \%$ & $51-75 \%$ & $76-100 \%$ & $101-150 \%$ & $151 \%-$ \\
\hline $0-50 \%$ & 6.60 & 42.86 & 28.57 & 14.29 & 14.29 & 0.00 \\
\hline $51-75 \%$ & 26.42 & 10.71 & 39.29 & 35.71 & 10.71 & 3.57 \\
\hline $76-100 \%$ & 30.19 & 0.00 & 15.63 & 46.88 & 34.38 & 3.13 \\
\hline $101-150 \%$ & 21.70 & 8.70 & 17.39 & 30.43 & 34.78 & 8.70 \\
\hline $151 \%-$ & 15.09 & 0.00 & 0.00 & 6.25 & 43.75 & 50.00 \\
\hline
\end{tabular}

Source: Own calculations.

Table 3. Transition probability matrix, $B D P p c, B i H=100,2010-2020$.

\begin{tabular}{|c|c|c|c|c|c|c|}
\hline \multicolumn{7}{|l|}{ GDP pc 2020} \\
\hline GDP pc 2010 & $\%$ of regions & $0-50 \%$ & $51-75 \%$ & $76-100 \%$ & $101-150 \%$ & $151 \%-$ \\
\hline $0-50 \%$ & 7.55 & 75.00 & 12.50 & 12.50 & 0.00 & 0.00 \\
\hline $51-75 \%$ & 20.75 & 0.00 & 63.64 & 31.82 & 4.55 & 0.00 \\
\hline $76-100 \%$ & 32.08 & 0.00 & 14.71 & 58.82 & 23.53 & 2.94 \\
\hline $101-150 \%$ & 28.30 & 0.00 & 6.67 & 10.00 & 83.33 & 0.00 \\
\hline $151 \%$ - & 11.32 & 0.00 & 0.00 & 0.00 & 50.00 & 50.00 \\
\hline
\end{tabular}

Source: Own calculations.

The data indicates a relative inconsistency of the distribution. The values on the diagonal of the probability matrix are quite low, especially in 1995-2010 matrix, suggesting a low probability of remaining in the same class of per capita GDP. This is summarised by stability index S (sum of the elements of the main diagonal divided with $n$ ) which takes the value of 0.42 in the first, and 0.66 in the second period.

Inconsistence is similarly pronounced at all classes of the distribution. In particular, $57.14 \%$ of the poorest municipalities in 1990 moved up to higher categories in 2010, while $50,00 \%$ of the regions in class [151\%-] in 1990 moved to lower classes in 2010. In general, for municipalities with per capita GDP lower than $\mathrm{BiH}$ average, movements towards upper categories were equally frequent as the movements down of the regions with per capita GDP above $\mathrm{BiH}$ average. Movements in both directions decreased in 2010-2020, but are still pretty high.

Municipalities that moved towards lower categories are often the ones with significant human casualties during the 1992-1995 war, entity line divided municipalities, and the municipalities with many refugees who never returned to their pre-war homes (municipalities with significant or majority pre-war shares of one ethnicity that is now situated in the entity or canton with other ethnic majority). Also, in many cases these are the municipalities with economy depending on one or few industrial capacities closed down after unsuccessfully privatised during 2000s.

\section{Conclusions}

Analysing the possibilities of dynamising growth opportunities of poor regions and improving unfavorable trends in comparison with the rich regions reveals the complexity of convergence problem. It also points to significant efforts that would be necessary to at least partially reduce development gaps and lower political, social and environmental tensions. Combining regression and distributional approach, this paper is testing convergence of local communities in Bosnia and Herzegovina. In last few decades the country was simultaneously facing transition from war to peace and from socialism to market economy. New administrative setting introduced with the Dayton peace agreement disrupted pre-war economic connections and resulted in more or less ethnically homogenous territories with more than thirty new often very small municipalities. Transition outcomes generally were rather disappointing.

All of these had significant impact on development dynamics at the local level. While regression analysis provide some evidence for unconditional beta-convergence, in a case of sigma convergence, results are mixed. Coefficient of variation is steadily decreasing indicating reduced dispersion of per capita GDP across municipalities. However, Sigma-convergence is not confirmed using Gini index calculations. It can be explained by different sensitivity properties of the two measures. Further investigation using two visual inspection instruments also provides no evidence for sigma convergence. These findings were expected in a way having in mind significant structural changes country went through after the 1992-1995 war. Transitional probability matrix data and Stability index indicates a relative inconsistency of the distribution suggesting a high probability of moving towards upper but also towards lower classes.

Research results suggest that serious assessments of convergence has to be based on a various approaches and instruments taking into account their complementarities. From 
the $\mathrm{BiH}$ perspective, research results can be useful for profiling and discussions about more balanced regional development policy in the future. The results can also be useful for the ongoing discussion on sustainability of current territorial organization of the country.

\section{References}

[1] Armstrong, H. W. (1995). "Convergence among Regions of the European Union, 1950-1990”. Papers in Regional Science, 74 (2), 143-152. (c).

[2] Barrios, S. and Strobl, E. (2005). "The Dynamics of Regional Inequalities", Economic Papers of the European Commission, 229, Brussels.

[3] Barro, R. J. and Sala-i-Martin, X. (1991). "Convergence across States and Regions". Brooking Papers on Economic Activity, 1 107-182.

[4] Barro, R. and Sala-i-Martin, X. (1992). "Convergence", Journal of Political Economy, 100, 223-251.

[5] Baumol, W. J. (1986). "Productivity Growth, Convergence, and Welfare: What the Long-Run Data Show". American Economic Review, 76 (5), 1072-1085.

[6] Benczes, I. \& Szent-Ivanyi, B. (2015). The European economy in 2014: Fragile recovery and convergence. JCMS: Journal of Common Market Studies, 53, 162-180. https://doi.org/10.1111/jcms. 12266

[7] Bićanić, I., Deskar-Škrbić, M. \& Zrnc, J. (2016). A Narrative Explanation of Breakpoints and Convergence Patterns in Yugoslavia and its Successor States 1952-2015. The wiiw Balkan Observatory Working Papers 122.

[8] Cass, D. (1965). "Optimum Growth in an Aggregative Model of Capital Accumulation”. Review of Economic Studies, 32, 233-240.

[9] Chatterji, M. (1992). "Convergence Clubs and Endogenous Growth". Oxford Review of Economic Policy, 8 (4), 57-69.

[10] Cowell, F. (1980). "On the Structure of Additive Inequality Measures", Review of Economic Studies, 47, 521-31.

[11] Cuadrado-Roura, J. R., Mancha-Navarro, T. and Garrido-Yserte R. (2000). "Convergence and Regional Mobility in the European Union" 40th Congress of the European Regional Science Association, Barcelona.

[12] De la Fuente, A. (2000). "Convergence Across Countries and Regions: Theory and Empirics". CEPR Discussion Paper No. 2465, London: CEPR.

[13] Durlauf, S. N. and Quah, D. T. (1999). "The New Empirics of Economic Growth". In Taylor, J. and Woodford, M. (Eds.), Handbook of Macroeconomics, Amsterdam: North-Holland.

[14] Eckey H.-F. and Türck, M. (2006). “Convergence of EU-Regions: A Literature Review", Discussion Paper at the Economic Department of the University of Kassel, 86/06, Kassel.

[15] Fabiani, S. and Pellegrini, G. (1997). "Education, Infrastructure, Geography and Growth: An Empirical Analysis of the Development of Italian Provinces". Temi di discussione No. 323, Roma: Banca d'Italia.
[16] Fagerberg J. and Verspagen, B. (1996). "Heading for Divergence? Regional Growth in Europe Reconsidered". Journal of Common Market Studies, 34 (3), 431-448.

[17] Friedman, M. (1992). “Do Old Fallacies Ever Die?". Journal of Economic Literature, 30 (4), 2129-2132.

[18] Hofer, H. and Wörgötter, A. (1997). "Regional Per Capita Income Convergence in Austria”. Regional Studies, 31 (1), $1-12$.

[19] Matkowski, Z. \& Próchniak, M. (2004). Economic convergence in the EU accession countries. Composite Indicators of Business Activity for Macroeconomic Analysis, RIED Papers and Proceedings', vol. 74), SGH, Warsaw, 405-425.

[20] Martin, R. (2001). "EMU versus the Regions? Regional Convergence and Divergence in Euroland". Journal of Economic Geography, 1 (1), 51-80.

[21] Maurseth, P. B. (2001). "Convergence, Technology and Geography". Structural Change and Economic Dynamics, 12 (3), 247-276.

[22] Monfort, P. (2008). "Convergence of EU regions Measures and evolution”, Directorate-General for Regional Policy Working Papers Series, No 01/2008, Brussels.

[23] Nagy, S. G. and Siljak, Dz. (2019). "Do Transitional Countries Converge towards the European Union?", Baltic Journal of European Studies, Vol. 9, No. 1 (26).

[24] Neven, D. and Gouyette, C. (1995). "Regional Convergence in the European Community". Journal of Common Market Studies, 33 (1), 47-65.

[25] Niebuhr, A. (2001). "Convergence and the Effects of Spatial Interaction". Jahrbuch für Regionalwissenschaft, 21 (2), 113-133.

[26] Overman, H. and Puga, D. (2002). "Unemployment clusters across Europe's regions and countries", Economic Policy, CEPR, CES, MSH, vol. 17 (34), 115-148.

[27] Quah, D. T. (1993). "Galton's Fallacy and Tests of the Convergence Hypothesis". Scandinavian Journal of Economics, 95 (4), 427-443.

[28] Quah, D. (1996). "Empirics for Economic Growth and Convergence", European Economic Review, 40, 1353-1375.

[29] Quah, D. (1997). "Empirics for Growth and Distribution. Strati $\neg$ cation, Polarization and Convergence Clubs", Journal of Economic Growth, 2, 27-59.

[30] Sala-i-Martin, X. (1996). "Regional cohesion: Evidence and Theories of Regional Growth and Convergence", European Economic Review, 40, 1325-1352.

[31] Solow, R. (1956). "A Contribution to the Theory of Economic Growth", Quarterly Journal of Economics, 70, 1, 65-94.

[32] Swan, T. W. (1956). "Economic Growth and Capital Accumulation". Economic Record, 32 (63), 334-361.

[33] World Bank (1999). Inequality: Methods and Tools, World Bank's Web Site on Inequality, Poverty, and Socio-economic Performance, http://www.worldbank.org/poverty/inequal/index.htm 